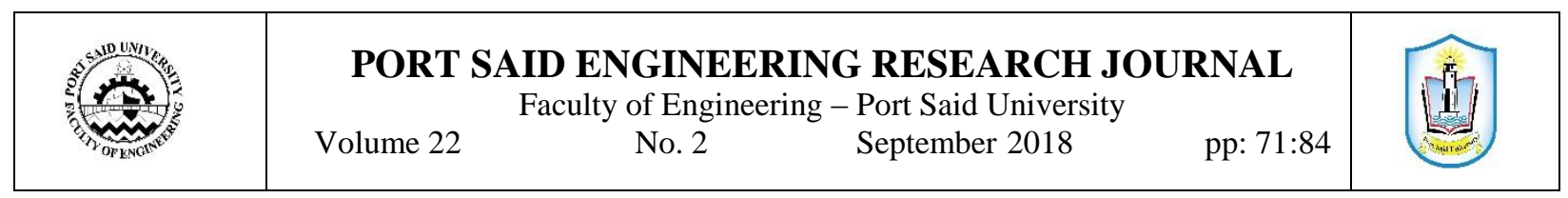

\title{
The Effect of Wall Shear Stress and Viscous Heating on Nanoscale Flow
}

\author{
Mohamed M Elsabahy ${ }^{1}$, Ahmed Sharaf Abdelhameed ${ }^{2}$, Yassen El-Sayed Yassen ${ }^{3}$
}

\begin{abstract}
The effect of wall shear stress and viscous heating on nano scale flow properties and boundary conditions is presented. Molecular dynamics (MD) simulations is implemented to handle nano scale force-driven Poiseuille flow bounded by two parallel planner plates with liquid Argon subjected to wide range of wall shear stress. The excessive generated viscous heating is removed via adaptive thermal interacting wall model leading to nearly constant mean fluid temperature. The predicted results showed the classification of controlled and uncontrolled temperature flow mode (CTFM, UTFM) related to the capability of adjusting mean fluid temperature up to wall shear stress limit (WSSL). The relevant change of temperature profile and depletion layer thickness that depend on the applied wall shear stress is noticeable. It is clear that the change of depletion layer thickness influences the effective channel height and the average density. It is noticed the implementation of density and temperature on the change of fluid pressure in both CTFM and UTFM. Owing to the significant increase in pressure and temperature beyond WSSL, a supercritical fluid state is noticeable. The slip length and the fluid inhomogeneity are reported to be strongly dependent on the applied wall shear stress.
\end{abstract}

Keywords: Molecular dynamics simulations, Viscous heating, Force-driven liquid argon flow, Fluid inhomogeneity, slip flow, Stick flow, Slip length

\section{Introduction}

Recently, there has been an increasing interest in the nanofluidic field which advances rapidly causing a remarkable leap in both phenomena and applications related to the classical disciplines such as physics, chemistry, engineering, and biology etc. Understanding the liquid mass, momentum and energy transport in/around nanoscale geometries is a major area of interest in nanofluidic research field because of the wide range applications including molecular separation such as water desalination and filtration through nano-bores membranes[12, 20, 44, 52]; nano-size liquid film lubrication; molecular and nano particles drug delivery across biological membranes[11, 18, 40, 54]; chip level cooling[28, 42]; surface wettability enhancement; and micro/nano electro-mechanical systems applications [28, 42].

Molecular dynamics (MD) simulations are usually used to investigate the nanoscale flow characteristics. In recent years, there has been an increasing amount

\footnotetext{
${ }^{1}$ Demonstrator of Mechanical power Eng., Faculty of Eng., Suez Canal University.Email:Mohamed_Elsabahy@eng.suez.edu.eg

${ }^{2}$ Prof. of Mechanical power Eng., Faculty of Eng., Port Said University.Email: sh_ahmed99@yahoo.com

${ }^{3}$ Dr. of Mechanical power Eng., Faculty of Eng., Port Said University. Email: y_yassen70@yahoo.com
}

of literature on the potential of channel height and shear rate on: the fluid properties (density, viscosity); flow characteristics such as velocity profile and mass flow rate; and boundary conditions, i.e. slip length. Previous studies have reported that the average density in nano-channel of smaller heights becomes lower than the density at the bulk flow region $[49,51$, 53] for force driven flow. In addition, the magnitude of the average density has been found to decrease with the reduction in the channel height[7, 37, 43] and to be independent on magnitude of the applied force (wall shear stress) [39, 41, 50].

The depletion layer, where the fluid atoms rarely exist, was introduced by several studies. For example, many studies assumed that the thickness of this layer extends from the center of the wall atoms (in contact with fluid) to the location of maximum peak of the density profile $[5,8,9,25]$ referring to the location of the hydrodynamic boundary. Another study assumed the location of the hydrodynamic boundary to be at the nearest location next to the wall where the density reaches $10 \%$ of the average value[21].

The fluid viscosity was reported to be strongly dependent on highly confined channel size[15]. Several MD studies reported both decrease[41, 45] and increase[43] of apparent viscosity with increasing nano-channel size. Previous studies indicated the ability to measure viscosity using both 
equilibrium molecular dynamics (EMD) and nonequilibrium molecular dynamics (NEMD) simulations. In the former, Green-Kubo relations[1] and Einstein relation[19] are used to calculate viscosity[32, 43, 45, 46], while in the later, the viscosity can be extracted via Newton's viscosity law's from the system where the fluid is sheared by moving bounding walls, by deformation of the simulation box[13, 14] or just through applying external body force[41, 43].

For decades, the slip at fluid solid interface has been under extensive studies[10, 23, 26, 33]; and many recent experiments showed the violation of noslip boundary condition. Multiple studies have been conducted to investigate the effect of applied shear rate, channel size[29, 43], nanotube diameter[41, 45], pressure[27], ratio of wall-liquid density[47], and surface wettability (hydrophobicity)[7, 35]on the slip length.

Several studies have reported unbounded slip length at high shear rate[36, 48] while bounded behavior revealed by other studies[30, 31, 34]. These studies concluded that the contradictory of the unbounded slip is due to using rigid wall model. The viscous heating at high shear has been found to have a remarkable effect due to a drastic change of the fluid temperature compared with low shear rate[6, 24]. The contradiction between bounded and unbounded behavior was attributed to the effect of temperature difference generated by the viscous heating[34, 55].

Two mechanisms about slip and friction were reported. The first mechanism is due to the roughness of the solid wall potential undulations which induce forces resisting the motion of adsorbed fluid layers $[4,31]$. The second one is due to the momentum transfer through collision between fluid atoms and adjacent solid wall atoms[30, 34].

Turning to the wall models used in Molecular dynamic simulations, major trend of previous studies adopts frozen wall model in which the wall atoms are fixed to their equilibrium position. In this model, direct thermostat is applied directly to the fluid atoms to control the fluid temperature; the viscous heating is irrelevant; uniform fluid temperature is obtainable; and the fluid properties seem to be independent on the applied body force (shear rate)[16, 21]. However, this model would expect to be unrealistic and far away from practice. Another model, the thermal wall model, is considered to be realistic where the effect of viscous heating is included because of no direct thermostat on the fluid atoms. Instead, the thermostat is applied on the vibrating wall atoms to fix the wall temperature. Unfortunately, the fluid temperature becomes uncontrolled with changing applied body force (shear rate) due to the effect of viscous heating[3].

Based on the previous studies, the viscous heating effect on nanoscale flow with thermal wall model alongside a controlled mean fluid temperature is not included.

The present paper aims to investigate the effect of wall shear stress on fluid properties and boundary conditions for force driven nanoscale flow of liquid argon bounded by two parallel planner plates. Also, the determination of the wall shear stress range, where the mean fluid temperature is successfully controllable, is considered.

\section{Methodology and Simulations}

\subsection{Molecular Dynamics Simulations}

Molecular dynamics simulations are implemented to investigate the nanoscale flow of liquid argon confined between two parallel walls. Lennard-jones (LJ) units, as shown in Table 1, are used to represent all physical quantities in this paper. Each wall consists of 5 layers of wall atoms structured in a face centered cubic lattice with a density $\rho_{w}=1 \mathrm{mo}^{-3}$. The channel height, referring to the separation distance between the center of innermost layers of the upper and lower bounding walls, is set at $h=15 \sigma$ such that the region dominantly affected by walls becomes comparable in size to the bulk flow region. In order to avoid 'wrap-around' effects caused by the periodic boundaries, the domain is extended by length $15.874 \sigma$ in $x-$ and $z-$ directions, as can be seen in Fig. 1, where periodic boundary conditions are applied to create an infinite domain. The mass for each wall or fluid atom is taken as $m_{f}=m_{w}=1 \mathrm{~m}$.

Each pair of atoms in the given molecular system interacts according to Lennard-Jones (LJ) potential that can be represented as:

Table 1 Lennard-jones units

\begin{tabular}{lll}
\hline Basic units & Symbol & Parameter for Argon \\
\hline Mass & $m$ & $6.69 \times 10^{-26} \mathrm{~kg}$ \\
Length & $\sigma$ & $3.405 \times 10^{-10} \mathrm{~m}$ \\
Energy & $\epsilon$ & $1.65 \times 10^{-21} \mathrm{~J}$ \\
Temperature & $\epsilon / k_{B}$ & $119.8 \mathrm{~K}$ \\
Time & $\tau$ & $2.1681 \times 10^{-12} \mathrm{~s}$ \\
\hline
\end{tabular}


$U\left(r_{i j}\right)=\left\{\begin{array}{cc}\epsilon_{i j}\left[\left(\sigma_{i j} / r_{i j}\right)^{12}-\left(\sigma_{i j} / r_{i j}\right)^{6}\right], & r_{i j}<r_{c} \\ 0, & r_{i j} \geq r_{c}\end{array}\right.$

where $U\left(r_{i j}\right)$ is the potential function between two atoms with indices $i, j$ separated by distance $r_{i j}$; and $r_{c}$ is cutoff radius set to $3.2 \sigma$. Parameters, $\epsilon_{i j}$ and $\sigma_{i j}$, are binding energy and collision distance, respectively. Both have different values based on the interacted pair of atoms as shown in Table 3.

In order to initially obtain Argon at liquid state during equilibrium simulation case (f0) (see Table 2), when no external body force subjected to the fluid, both fluid density and fluid temperature are chosen carefully according to the phase diagram of Argon. The bulk density is almost set at $\sim 0.827$ by inserting 2985 atoms of Argon in the available volume between the bounding walls, and the fluid temperature is adjusted at $\sim 1 \epsilon / k_{B}$.

To investigate the effect of the wall shear stress on the fluid properties and boundary conditions, ten cases of nonequilibrium simulations, as shown in Table 2, are carried out by applying an external body force on the fluid atoms. Derived from Navier Stokes equations for Poiseuille flow, the relation between wall shear stress and external body force follows:

$\mathrm{P}_{\mathrm{xy}, \mathrm{init}}=\left.\mu \frac{d u}{d y}\right|_{y=0}=\frac{\rho_{e} a h_{e}}{2}$

where $\mathrm{P}_{\mathrm{xy}, \text { init }}$ is initially assumed wall shear stress; $\mu$ is fluid dynamic viscosity; $\rho_{e}$ and $h_{e}$ are effective density and effective channel height at equilibrium case (f0), both will be introduced in the next section; and $a$ is body force acceleration (gravity like) which here is equivalent to external body force $\left(\mathrm{f}_{\text {ext }}=\right.$ $m_{f} a=1 \times a$ ) due to the use of liquid argon with mass $m_{f}=1 \mathrm{~m}$. The external body force is increased every $4 \times 10^{6}$ steps of time $0.0005 \tau$ per step. Each set (case) of $4 \times 10^{6}$ steps are divided equally into $2 \times 10^{6}$ time steps for reaching equilibrium followed by another $2 \times 10^{6}$ time steps to export the fluid and wall atoms trajectories for

Table 3 Interaction parameters of Lennard-Jones potential

\begin{tabular}{ccc}
\hline$i j$ & $\epsilon_{i j}(\epsilon)$ & $\sigma_{i j}(\sigma)$ \\
\hline Wall-Wall & 0.16 & 1 \\
Wall-Fluid & 0.4 & 1 \\
Fluid-Fluid & 1 & 1 \\
\hline
\end{tabular}

further post-processing as discussed in the next section.

In an attempt to maintain the mean fluid temperature constant at $1 \epsilon / k_{B}$ during nonequilibrium simulations, thermal wall model is implemented. In that type of model, the wall atoms are allowed to vibrate while being tethered to their equilibrium position via harmonic potential that generates spring force, $\mathrm{F}_{e, i}=-k\left(r_{i}-r_{i, o}\right)$, where $r_{i}$ is atom position, $r_{i, o}$ is initial equilibrium position in frozen lattice, and $k$ is spring constant[2] set to $75 \epsilon / \sigma^{2}$ based on Lindemann criteria for melting[17]. The velocity of the vibrating atoms is automatically regulated through a feedback controller to adjust the wall temperature at the appropriate value that enable the walls to absorb the excessive generated viscous heating and consequently maintain the mean fluid temperature constant as possible. Moreover, The Gaussian thermostat is employed upon the wall atoms due to its fast response.

All MD simulations are performed using LAMMPS (Large-scale Atomic/Molecular Massively Parallel Simulator), a free available software; and the velocity of fluid atoms was initialized via MaxwellBoltzmann velocity distribution.

\subsection{Molecular Dynamics Post-processing}

To calculate the fluid properties and flow

Table 2 Simulated cases for the range of applied body force corresponding the range of initially assumed wall shear stress and the actually obtained results of wall shear stress.

\begin{tabular}{cccc}
\hline Case \# & $\mathrm{P}_{\mathrm{xy}, \mathrm{init}}\left(\epsilon / \sigma^{3}\right)$ & $\mathrm{f}_{\mathrm{ext}}(\epsilon / \sigma)$ & $\mathrm{P}_{\mathrm{xy}, \mathrm{w}}\left(\epsilon / \sigma^{3}\right)$ \\
\hline $\mathrm{f} 0$ & 0 & 0 & 0 \\
$\mathrm{f} 1$ & 0.1647 & 0.0286 & 0.1685 \\
$\mathrm{f} 2$ & 0.3293 & 0.0571 & 0.3343 \\
$\mathrm{f} 3$ & 0.4940 & 0.0857 & 0.5009 \\
$\mathrm{f} 4$ & 0.6586 & 0.1143 & 0.6703 \\
$\mathrm{f} 5$ & 0.8233 & 0.1429 & 0.8339 \\
$\mathrm{f} 6$ & 0.9879 & 0.1714 & 0.9945 \\
$\mathrm{f} 7$ & 1.1526 & 0.2000 & 1.1681 \\
$\mathrm{f} 8$ & 1.3173 & 0.2286 & 1.3316 \\
$\mathrm{f} 9$ & 1.4819 & 1.4938 & 1.4938 \\
$\mathrm{f} 10$ & 1.6466 & 1.6354 & 1.6354 \\
\hline
\end{tabular}




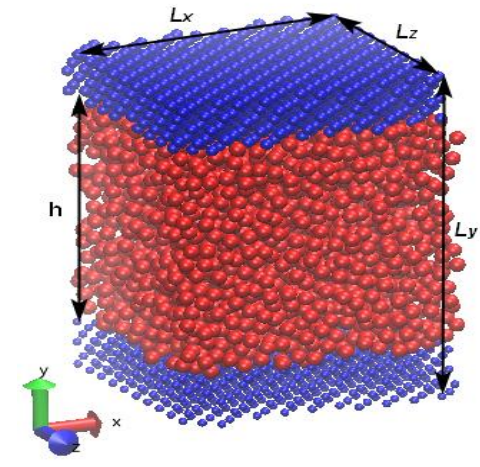

Fig. 1 Snapshot of Argon molecules bounded by the FCC structured walls

characteristics averaged along the time, the postprocessing of atoms trajectories resulting from MD simulation is performed through the use of statistical mechanics relations. Besides, binning method as a spatially averaging method (The domain is divided into smaller bins) is also adopted for the purpose of obtaining the distributions and the profiles of the properties across y direction of the channel. The bin size of $0.1 \sigma$ is chosen to capture fluid inhomogeneity details and to avoid empty bins and discontinuity in profiles as well.

A general schematic of the Post-processing is presented in Fig. 2. To obtain the density profile, $\rho$, that is similar to what is shown in Fig. 2b, the density was locally calculated in each bin through

$\rho_{\text {bin }}=m_{f} \frac{N_{\text {bin }}}{V_{\text {bin }}}$

where $N_{b i n}$ is the number of atoms inside a bin of volume $V_{b i n}$ and $m_{f}=1 m$ is mass of fluid atom. Regarding the 'depletion layer thickness' $(\delta)$, it is here defined as the normal distance from the $x z$-plane (represented by vertical solid line in Fig. 2) at the center of innermost layer of the wall (upper or lower) to the hydrodynamic boundary which is the nearest location in y-direction (represented by vertical dash line) where the local value of the density reaches $10 \%$ of the bulk density calculated in the core of channel (see Fig. 2b). Therefore, the effective channel height, $h_{e}$, which define the effective volume that actually occupied by fluid atoms (here in $\mathrm{y}$ direction) is calculated by $\mathrm{h}_{\mathrm{e}}=\mathrm{h}-2 \delta$, where $\mathrm{h}$ is the original height.

The effective density, $\rho_{\mathrm{e}}$, is obtained by calculating the mean for all values of the density profile within the effective channel height. To quantitively represent the strength of the fluid inhomogeneity near wall, the term 'contact density' $\left(\rho_{\mathrm{c}}\right)$ is introduced which is calculated by taking the mean of the 1st maximum peaks next to the upper and lower walls presented in the density profile.

According to the equipartition theorem, the fluid temperature (see Fig. 2b) is locally obtained for each bin as follows:

$T_{\text {bin }}=\frac{2}{3 N_{\text {bin }} k_{B}} \sum_{i=1}^{N_{\text {bin }}} \frac{1}{2} m_{i}\left(\dot{r}_{i}-u_{\mathrm{bin}}\right)^{2}$

Where $T_{b i n}$ is the temperature in the bin, $\dot{r}_{i}$ is the total velocity for atom with index $i, u_{\mathrm{bin}}$ is bin average velocity, and $k_{B}$ is Boltzmann constant. The mean value of temperature at the locations of the two maximum peaks of density profile refers to the fluid contact temperature $\left(\mathrm{T}_{\mathrm{c}}\right)$ while the value at the channel core refers to fluid core temperature ( $\left.\mathrm{T}_{\text {core }}\right)$.

The velocity profile, $u$, is obtained by calculating the velocity, $u_{\text {bin }}$, in each bin in the domain

$u_{\text {bin }}=\left(\sum_{i=1}^{N_{\text {bin }}} \dot{r}_{i}\right) / N_{\text {bin }}$

The 2nd order polynomial fit, $u_{f i t}(y)=b 1 y^{2}+$ $b 2 y+b 3$, of the velocity profile is then extracted as highlighted in Fig. 2c in order to be further used to represent quantitively the relaxation or the stick of the fluid near wall in the term of 'slip length' $\left(L_{s}\right)$ which is determined by the distance from the location of the hydrodynamic boundary (vertical dash line) to the zero value of the extrapolation of the extracted velocity fit, $u_{f i t}(y)$. The slip length may be zero, positive and negative depending on the wall boundary conditions (no-slip, slip and stick), respectively.

The strain rate, $\gamma$, can be represented in 2 ways as highlighted in Fig. 2e. The first is by applying central finite differences, $\gamma_{b i n, k}=\left(u_{b i n, k+1}-u_{b i n, k-1}\right) / 2 d y$, for all bins with index $k$ except for those at wall boundaries where the forward or the backward finite differences, $\gamma_{\text {cell }, i}=\left(u_{\text {cell }, i}-u_{\text {cell,i-1 } 1}\right) / d y$ or $\gamma_{\text {cell }, i}=$ $\left(u_{\text {cell }, i+1}-u_{\text {cell }, i}\right) / d y$, respectively, is used instead. However, this way has a certain drawback associated 


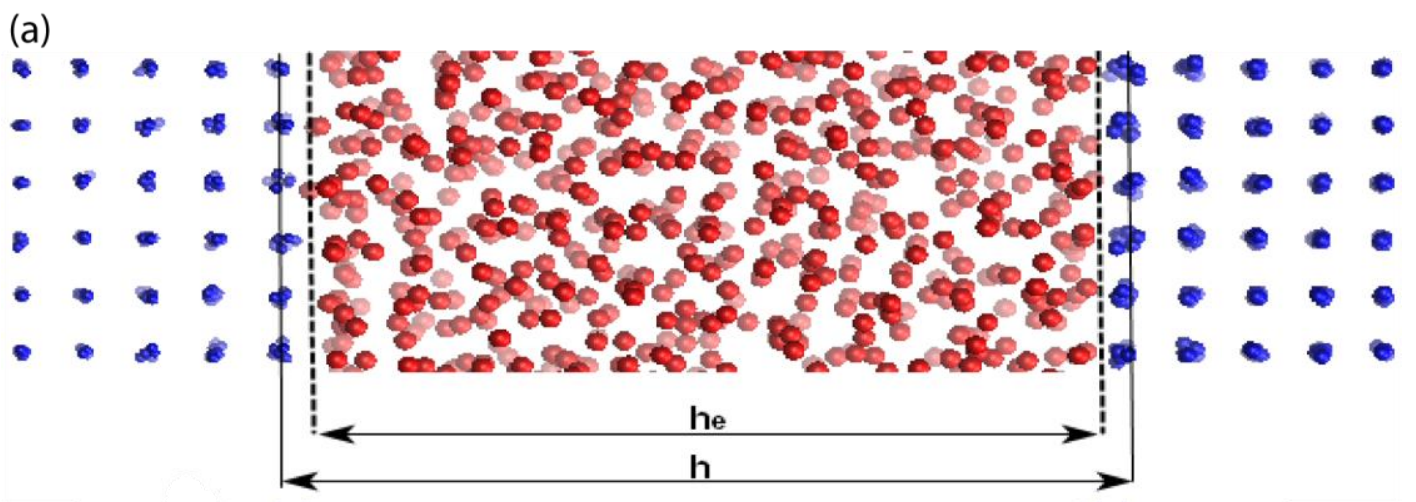

(b)

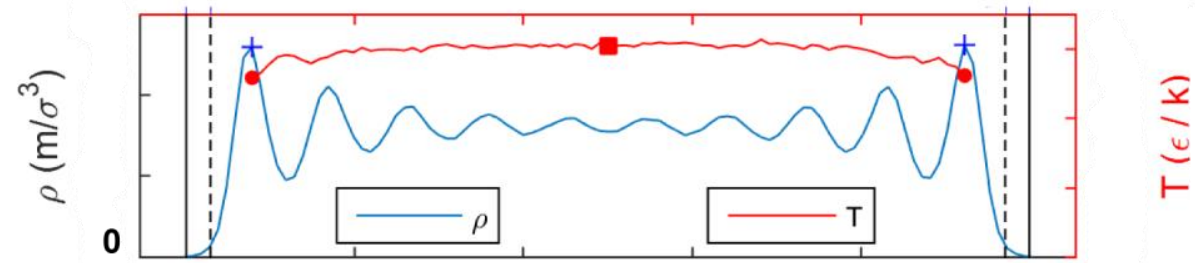

(c)

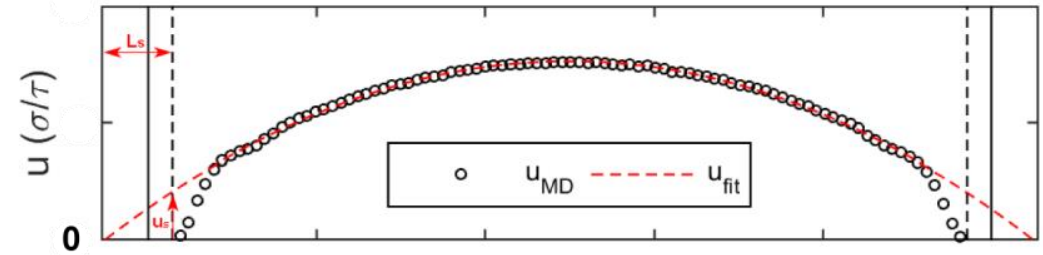

(e)

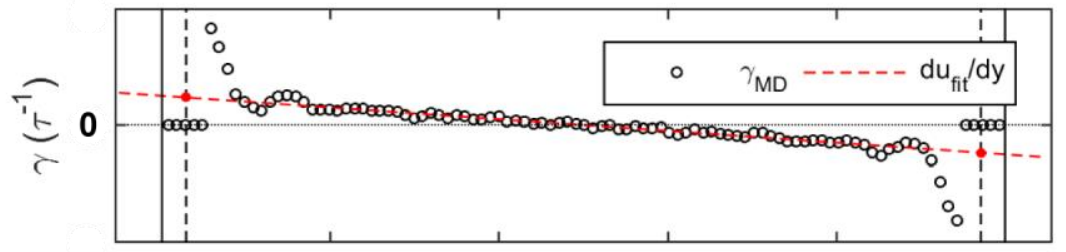

(f)

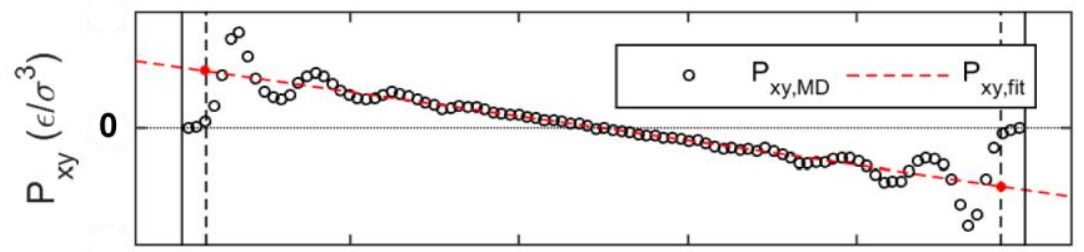

(g)

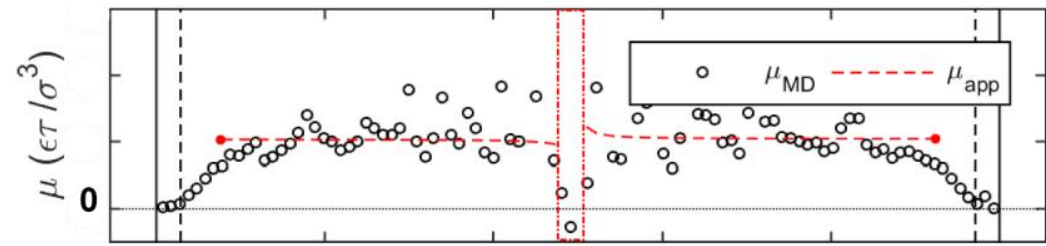

$$
\text { y }(\sigma)
$$

Fig. 2 Schematic of Post-processing for extracting fluid properties 
with determining the value of strain rate at wall due to the profile fluctuations within near-wall region and the uncertainty regarding the location of hydrodynamic boundary. Therefore, the second way adopted here is that the strain rate at wall is determined by the value of the first derivative of the extracted velocity fit at the location of hydrodynamic boundary.

The shear stress, $\mathrm{P}_{\mathrm{xy}}$, can be computed, see Fig. $2 \mathrm{f}$, using Irving-Kirkwood method[22]. To find the effect of wall shear stress $\left(\mathrm{P}_{\mathrm{xy}, \mathrm{w}}\right)$ on the fluid properties and the boundary conditions, it would be necessary to define how the wall shear stress is calculated. In this paper, the wall shear stress is assumed to be equivalent to the apparent wall shear stress which is defined by the value of the first order fit for shear stress, $\mathrm{P}_{\mathrm{xy}, \mathrm{fit}}(y)=c y+d$, at the location of the hydrodynamic boundary $(y=\delta)$.

Based on Newton's viscosity law's, $\mu=\mathrm{P}_{x y} / \gamma$, the viscosity distribution can be measured in two ways. The first is to calculate the viscosity using the original fluctuated profiles of both shear stress and strain (Fig. 2e and Fig. 2f), but the viscosity is highly scattered with high uncertainty in the average value. Therefore, the viscosity is calculated based on the replacement of $\mathrm{P}_{x y}$ and $\gamma$ with $\mathrm{P}_{\mathrm{xy}, \text { fit }}$ and $d u_{f i t} / d y$, respectively. The term 'effective viscosity', $\mu_{e f f}$, indicates the mean value for all values of the viscosity calculated using the second method (represented by dash line in Fig. 2g) excluding those values in the core of channel around the location of zero shear stress and zero strain.

The post-processing stage including both binning method and statistical mechanics relations were carried out using MATLAB code written by first author. More detailed information about MD simulations and statistical mechanics relations can be found in books such as Rapport[38], and Allen and Tildesley[1].

\section{Results and Discussion}

The effect of viscous heating on fluid properties and boundary conditions (BC) for nanoscale flow is clearly indicated through the influence of Wall Shear Stress and Viscous Heating on wall and fluid temperatures.

Fig. 3 shows the relation between shear stress $P_{x y}$ and channel height of four cases of wall shear stress. These cases are chosen based on the significant change noticed in the trends as it will be indicated. It can be seen that the shear stress profile $\mathrm{P}_{\mathrm{xy}}$ seems to be fluctuated near wall while in core it looks smooth and linear in trend. The fluctuations in $P_{x y}$ is attributed to the dominance of wall effect in interaction zone. It can be also noticed in Fig. 3 that as body force (or wall shear stress) increases the overall trend of shear stress profile increases over the whole channel. It can be seen that the locations of the fluctuations in the interaction zone are nearly constant up to a specific value of wall shear stress (case f7). Then, the location of the fluctuations suddenly drifts toward the wall (case f8 to f10). The wall shear stress $\mathrm{P}_{\mathrm{xy}, \mathrm{w}}$ is calculated for all cases (see Table 2) based on the linear fit of shear stress profiles for all cases as mentioned in methodology section (Sect. 2).

Fig. 4 illustrates the relationship between fluid temperature and the channel height for different cases of wall shear stress $\mathrm{P}_{\mathrm{xy}, \mathrm{w}}$. It can be seen that the temperature profiles are nearly uniform for small values of $\mathrm{P}_{\mathrm{xy}, \mathrm{w}}$. However, as a result of increasing wall shear stress, the temperature profiles seem to be curvier and more nonlinear in trend. More details are zoomed in Fig. 4(Left) regarding the region near wall

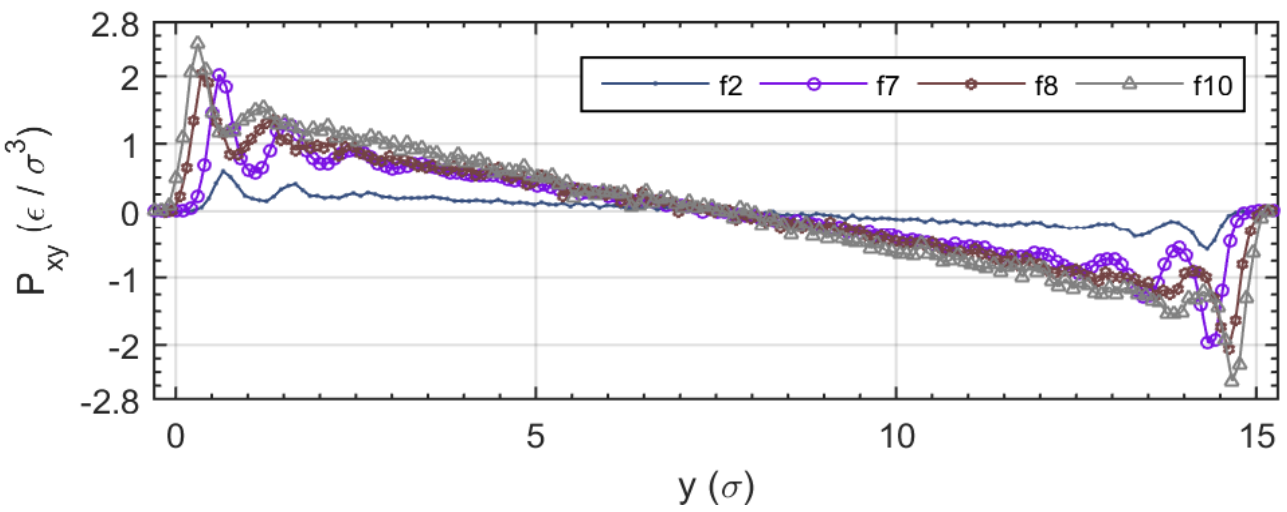

Fig. 3 Shear stress profiles of liquid Argon for selected non-equilibrium cases of different wall shear stress 
for cases from $\mathrm{f} 1$ to $\mathrm{f} 7$.

Fig. 5 illustrates mean wall temperature $\mathrm{T}_{\mathrm{wm}}$, mean fluid temperature $T_{f m}$, core temperature $T_{\text {core }}$, and contact temperature $T_{c}$ as function of wall shear stress. It is clear that mean wall temperature $T_{w m}$ decreases with increasing wall shear stress up to specific value $P_{x y, w}=1.1681 \epsilon / \sigma^{3}$ (case f7) at which $\mathrm{T}_{\mathrm{wm}}$ approaches the lowest obtainable temperature (absolute zero). In the present work, this value of $\mathrm{P}_{\mathrm{xy}, \mathrm{w}}$ is denoted by Wall Shear Stress Limit (WSSL). With regard to mean fluid temperature $\mathrm{T}_{\mathrm{fm}}$, It can be seen that at equilibrium (case f0) the mean fluid Temperature $\mathrm{T}_{\mathrm{fm}}$ is $\sim 0.990 \epsilon / \mathrm{k}$. Also, a slowly insignificant rise of mean fluid Temperature is noticed with increasing $P_{x y, w}$ up to $1.1681 \epsilon / \sigma^{3}$ (case f7). Beyond this value, a sudden increase of mean wall temperature followed by gradual noticeable
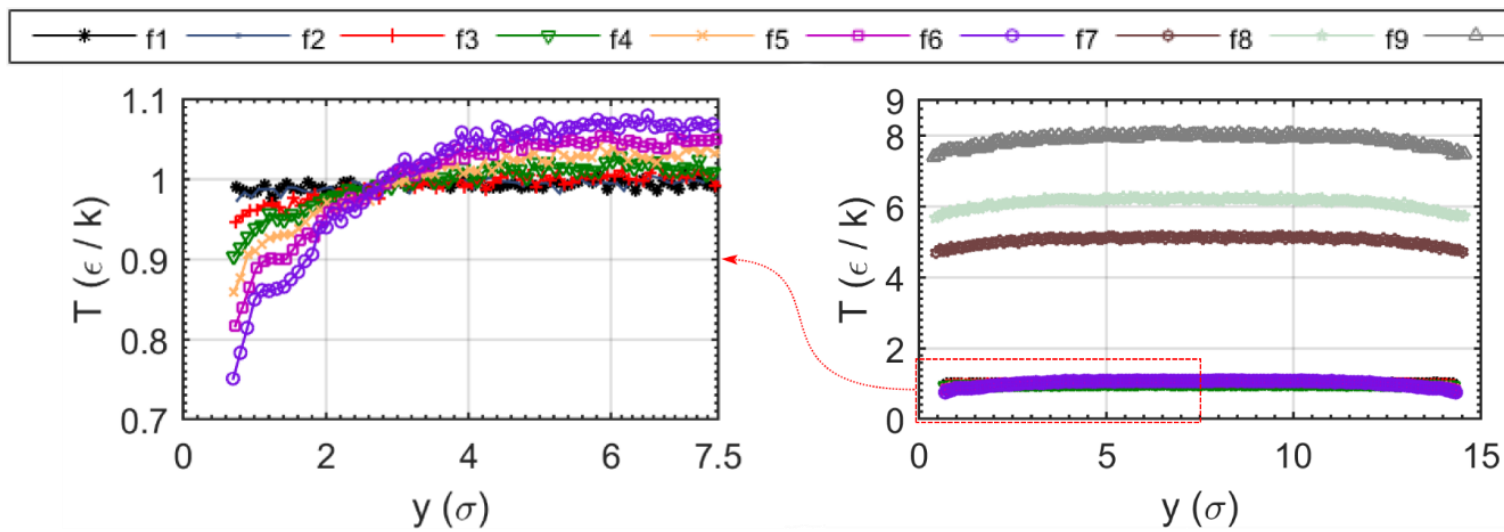

Fig. 4 Temperature profiles of liquid Argon for different wall shear stresses (right). The profiles in dash box are enlarged on the left side
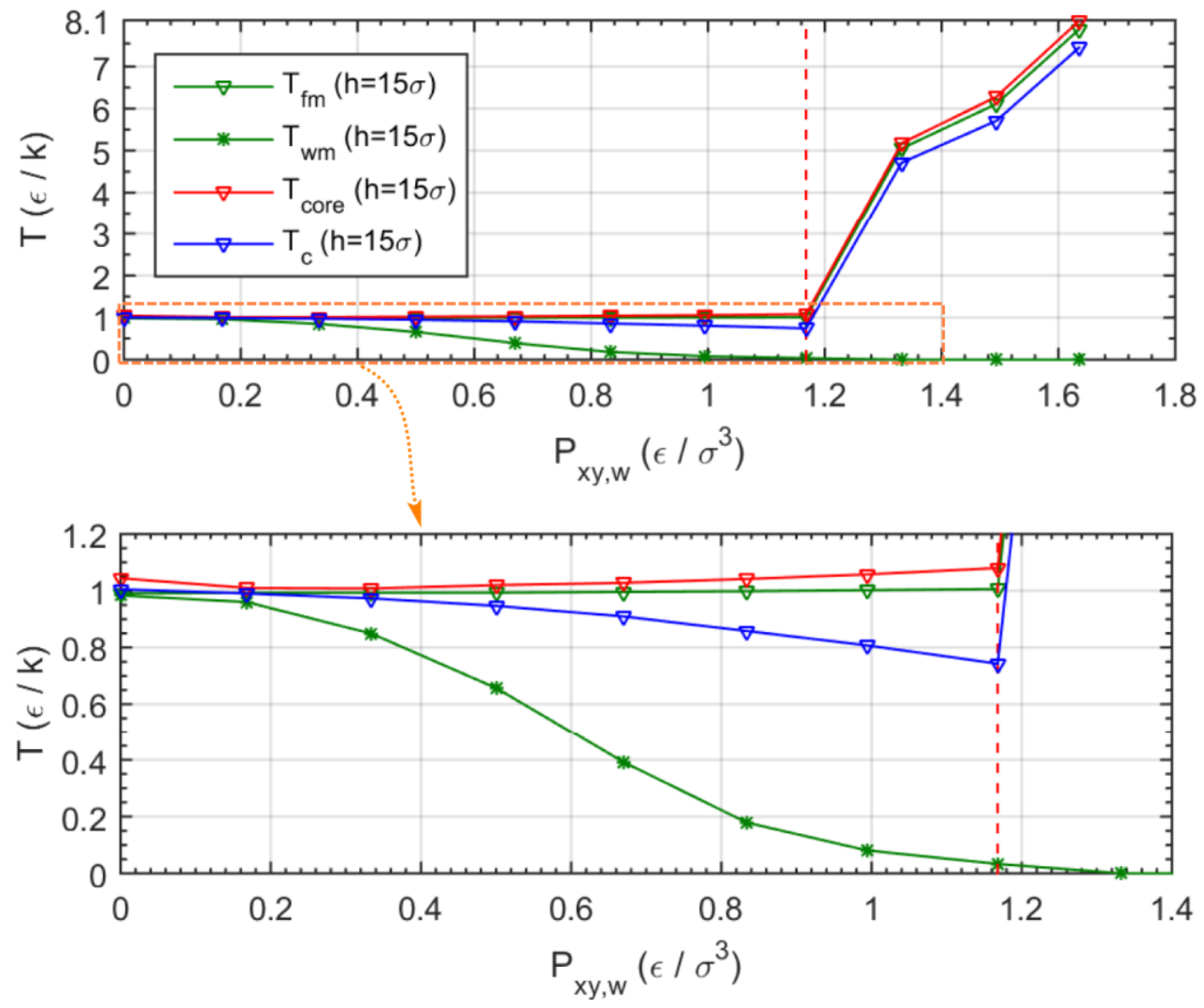

Fig. 5 The variation of mean fluid Temperature, mean wall temperature, core temperature, and contact temperature with wall shear stress for liquid Argon. The profiles contained in dash box are enlarged downside 


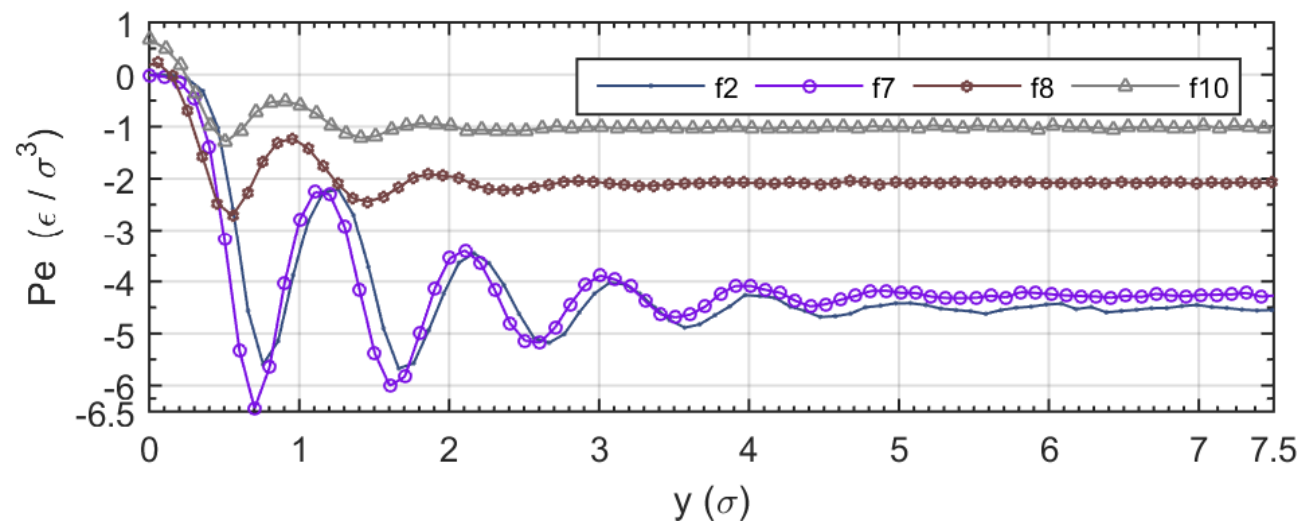

Fig. 6 Symmetrized potential energy profiles of liquid Argon for different cases of wall shear stress

increase of $\mathrm{T}_{\mathrm{fm}}$ is observed with increasing $\mathrm{P}_{\mathrm{xy}, \mathrm{w}}$. This finding indicates that both mean fluid temperature and viscous heating cannot be controlled after WSSL, and the flow can be classified into controlled (CTFM) and uncontrolled (UTFM) temperature flow mode before and after WSSL, respectively.

In case of CTFM, with increasing $\mathrm{P}_{\mathrm{xy}, \mathrm{w}}$, it is noticed that core temperature $\mathrm{T}_{\text {core }}$ increases slightly and contact temperature $\mathrm{T}_{\mathrm{c}}$ decreases while maintaining mean fluid temperature almost constant. This is attributed to the combined effect of the increasing in the generated viscous heating in the fluid while absorbing this heat through lowering the wall temperature. But in the case of UTFM, it can be seen that both $\mathrm{T}_{\text {core }}$ and $\mathrm{T}_{\mathrm{c}}$ increase considerably with increasing $\mathrm{P}_{\mathrm{xy}, \mathrm{w}}$ owing to the dominance effect of the viscous heating and the failure of controlling the mean fluid temperature.

Fig. 6 shows the profiles of symmetrized potential energy per unit volume $\mathrm{Pe}=\left(\sum_{i=1}^{N_{\text {bin }}} U(r)_{i}\right) / V_{\text {bin }}$ for cases of wall shear stress $\mathrm{P}_{\mathrm{xy}, \mathrm{w}}$ chosen to cover the range of low and high wall shear stress in both CTFM and UTFM, respectively. It is clearly indicated that the trend of Pe profiles decreases near wall while increases in the channel core for $\mathrm{P}_{\mathrm{xy}, \mathrm{w}}$ values up to WSSL (case f7). Also, it can be seen that the amplitude strength of fluctuations increases in particular near wall. In general, the different trends of Pe profiles near wall and channel core are attributed to nonlinear behavior of fluid temperature. After WSSL, the trend of Pe profiles increase considerably, while the amplitude strength of fluctuations decreases noticeably as a result of the significant increase of mean fluid temperature $\mathrm{T}_{\mathrm{fm}}$ with increasing wall shear stress $\mathrm{P}_{\mathrm{xy}, \mathrm{w}}$ in case of UTFM. With regard to the drifting in the locations of Pe fluctuations near wall, they tend to drift slightly toward the wall with increasing $\mathrm{P}_{\mathrm{xy}, \mathrm{w}}$ in particular case of CTFM, while drift at higher rate with increasing $\mathrm{P}_{\mathrm{xy}, \mathrm{w}}$ in case of UTFM. This behavior is attributed to the decrease of depletion layer thickness $\delta$ with increasing $\mathrm{P}_{\mathrm{xy}, \mathrm{w}}$.

Fig. 7 shows symmetrized density profile for wellchosen cases of wall shear stress $P_{x y, w}$.It is clearly indicated that there is a pattern between density profile and potential energy profile where the location of the fluctuations exist such that maximum density value is obtained at the low value of potential energy and vice versa. This pattern is expected because more atoms tend to exist at the locations where the value of potential energy becomes smaller. This explains the reasons behind: the increase of the fluid inhomogeneity (density fluctuation strength) in case of CTFM; the significant decrease with the transition to UTFM; and the drifting of the density profile fluctuations toward walls in both CTFM and UTFM.

Fig. 8 shows the relation between contact density $\rho_{\mathrm{c}}$ and wall shear stress $\mathrm{P}_{\mathrm{xy}, \mathrm{w}}$. It can be noticed that there is a slight change in $\rho_{\mathrm{c}}$ (inhomogeneous fluid) for low $\mathrm{P}_{\mathrm{xy}, \mathrm{w}}$ up to $\sim 0.67 \epsilon / \sigma^{3}$ (in CTFM) due to the insignificant differences in contact temperature $T_{c}$. Also, as $\mathrm{P}_{\mathrm{xy}, \mathrm{w}}$ increases up to WSSL at $1.1681 \epsilon / \sigma^{3}$, $\rho_{\mathrm{c}}$ is found to increase noticeably indicating the increase of $\rho_{\mathrm{c}}$ (relevant inhomogeneity). For increasing $\mathrm{P}_{\mathrm{xy}, \mathrm{w}}$ beyond WSSL, significant decreasing in $\rho_{\mathrm{c}}$ (less inhomogeneity) can be seen. In view of the trend of the contact density with wall shear stress, it is clearly indicated the strong dependence of the fluid inhomogeneity on the local temperature in the interaction zone (near wall). 


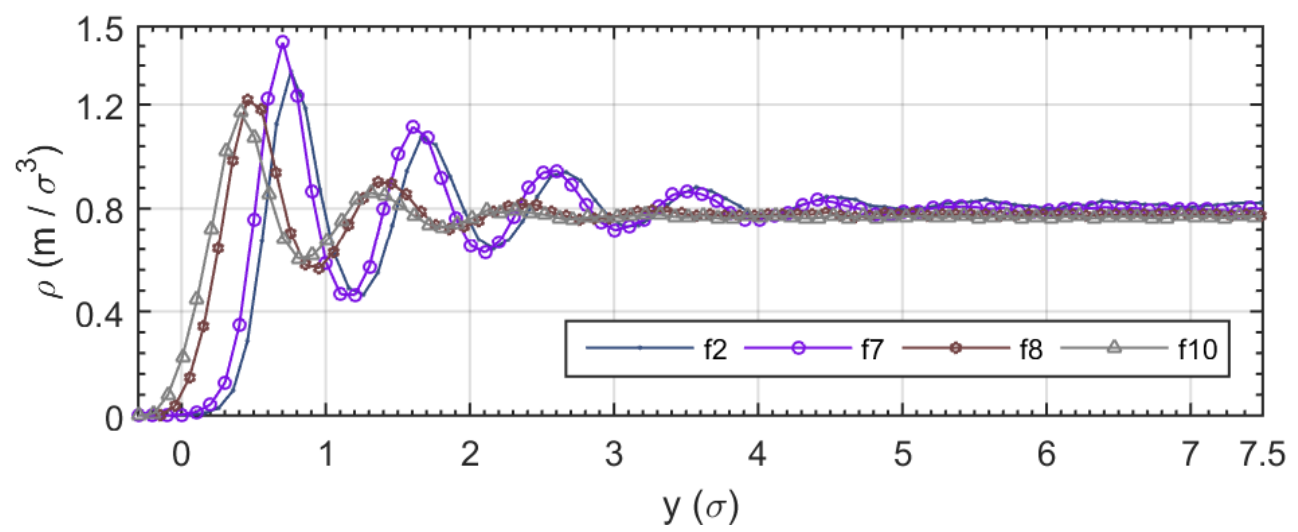

Fig. 7 Symmetrized density profiles of liquid Argon for different cases of wall shear stress

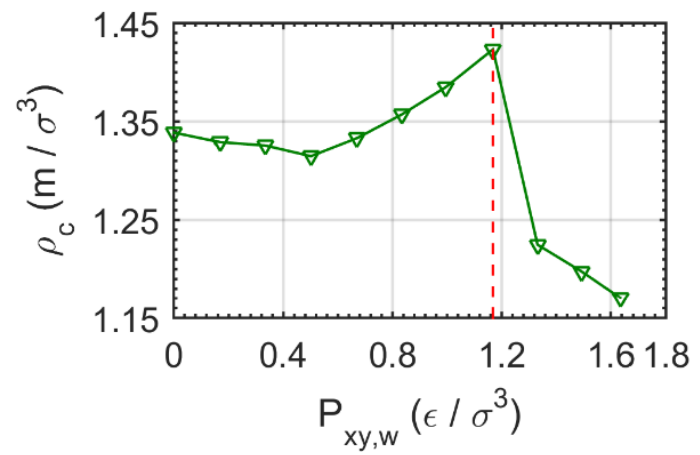

Fig. 8 Contact density variation with wall shear stress

Fig. 9 shows the relation between the depletion layer thickness $\delta$ and wall shear stress $\mathrm{P}_{\mathrm{xy}, \mathrm{w}}$. It is clear that $\delta$ decreases slightly in CTFM up to WSSL where $\delta$ decreases suddenly. In UTFM, the trend of $\delta$ seems to decrease at higher rate compared with CTFM. Also, negative values of $\delta$ can be noticed indicating that the effective channel height $h_{e}$ becomes larger than the original height $h$. It can be concluded that $\delta$ is positively dependent on the mean fluid temperature.

Fig. 10 illustrates the variation of effective density $\rho_{\mathrm{e}}$ with wall shear stress $\mathrm{P}_{\mathrm{xy}, \mathrm{w}}$. In case of CTFM, it can be seen that $\rho_{\mathrm{e}}$ decreases slightly as a result of slight decrease of depletion layer thickness $\delta$. At WSSL, it can be noticed that $\rho_{\mathrm{e}}$ decreases noticeably because of considerable decrease of $\delta$; but in case of UTFM $\rho_{\mathrm{e}}$, continues decreasing gradually. It is clearly indicated the dependence of the effective density on the depletion layer thickness.

Fig. 11 shows the mean pressure $\mathrm{P}_{\mathrm{m}}$ against different values of wall shear stress $P_{x y, w}$. In case of

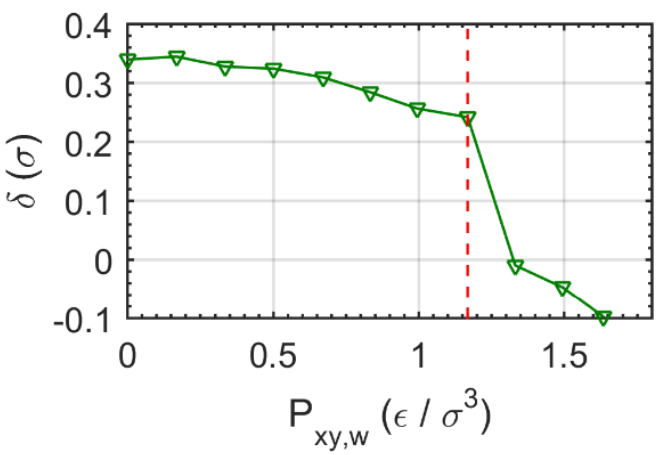

Fig. 9 Depletion layer thickness variation with wall shear stress

CTFM, it can be seen that $\mathrm{P}_{\mathrm{m}}$ barely changes owing to controlling the mean fluid temperature $\mathrm{T}_{\mathrm{fm}}$ in addition to the slight change of effective density $\rho_{\mathrm{e}}$. It is also noticed that $\mathrm{P}_{\mathrm{m}}$ increases suddenly at WSSL due to sudden increase in $T_{\mathrm{fm}}$. But in case of UTFM, it can be observed that $P_{m}$ continues to increase with increasing $\mathrm{P}_{\mathrm{xy}, \mathrm{w}}$. This is attributed to the dominance increase of $\mathrm{T}_{\mathrm{fm}}$ regardless of decreasing $\rho_{\mathrm{e}}$. It is clear the effect of $\mathrm{T}_{\mathrm{fm}}$ and $\rho_{\mathrm{e}}$ on increasing $\mathrm{P}_{\mathrm{m}}$ in CTFM and the dominance effect of $\mathrm{T}_{\mathrm{fm}}$ in case of UTFM.

Fig. 12 illustrates the variation of velocity profiles $\mathrm{u}$ in stream-wise direction for well-chosen cases of wall shear stress. It can be seen that ripples of velocity profiles exist in the interaction zone particularly for cases of CTFM at higher wall shear stress. This indicates to the remarkable influence of the fluid inhomogeneity (which also increases in CTFM at higher wall shear stress, see Fig. 8) on the fluid velocity in the interaction zone. In case of UTFM, the ripples strength in velocity profiles decreases in response to the reduction in fluid inhomogeneity. It is clear that velocity profiles at the 
fluid-solid interface exhibit smaller slip (stick) in UTFM. Further detail about slip and stick conditions will be discussed in the term of 'slip length'.

Fig. 13 shows the variation of both wall strain rate $\gamma_{\mathrm{w}}$ and effective apparent viscosity $\mu_{\text {eff }}$ against wall

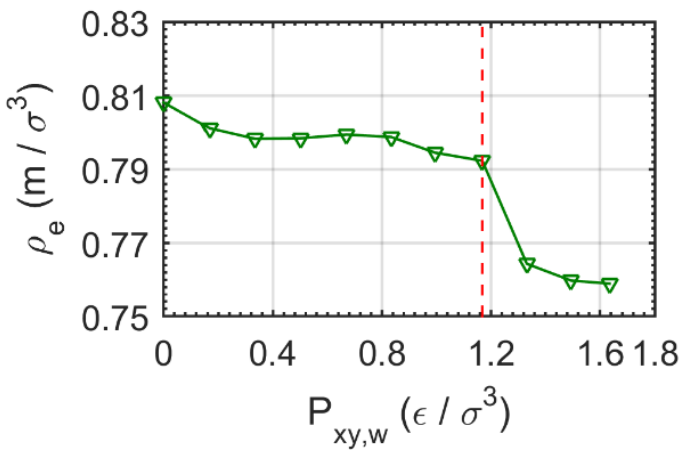

Fig. 10 Effective density variation with wall shear stress shear stress $\mathrm{P}_{\mathrm{xy}, \mathrm{w}}$. In case of CTFM, it is noticed that $\gamma_{\mathrm{w}}$ almost linearly increases as a result of increasing $\mathrm{P}_{\mathrm{xy}, \mathrm{w}}$ up to WSSL. At WSSL, it is observed that the trend of $\gamma_{\mathrm{w}}$ changes suddenly due to rapid increase in $\mathrm{T}_{\mathrm{fm}}$ and consequently sudden decrease of fluid

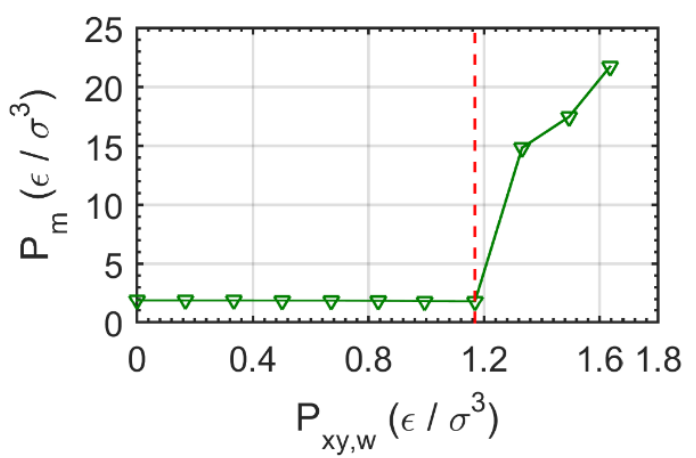

Fig. 11 Mean pressure variation with wall shear stress
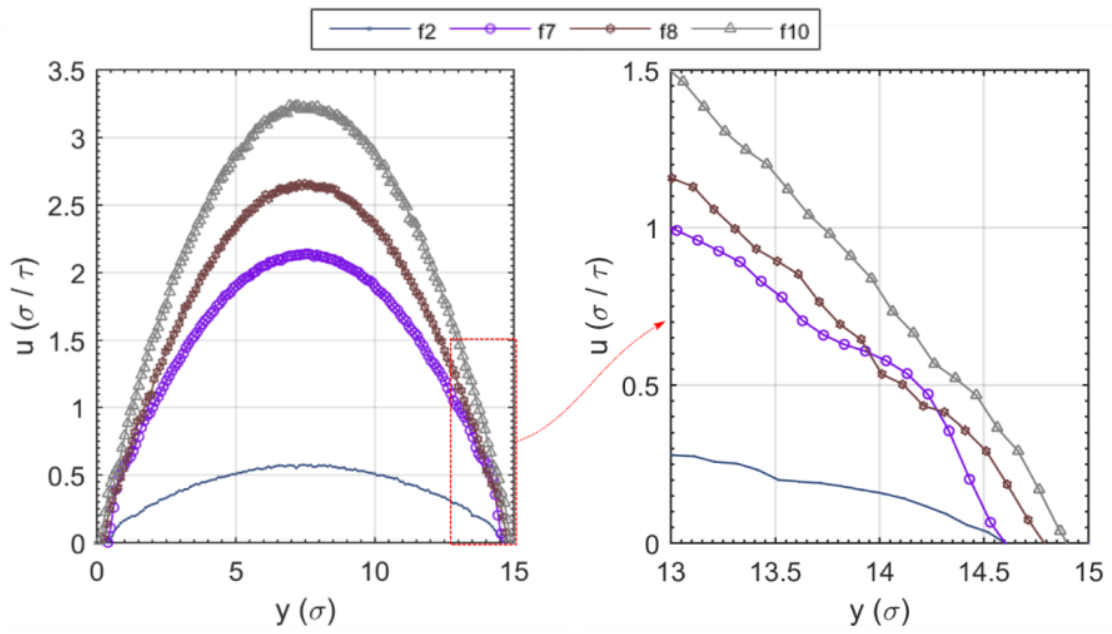

Fig. 12 Velocity profiles of liquid Argon for different cases of wall shear stress. The selected profiles in dash box are enlarged on the right side

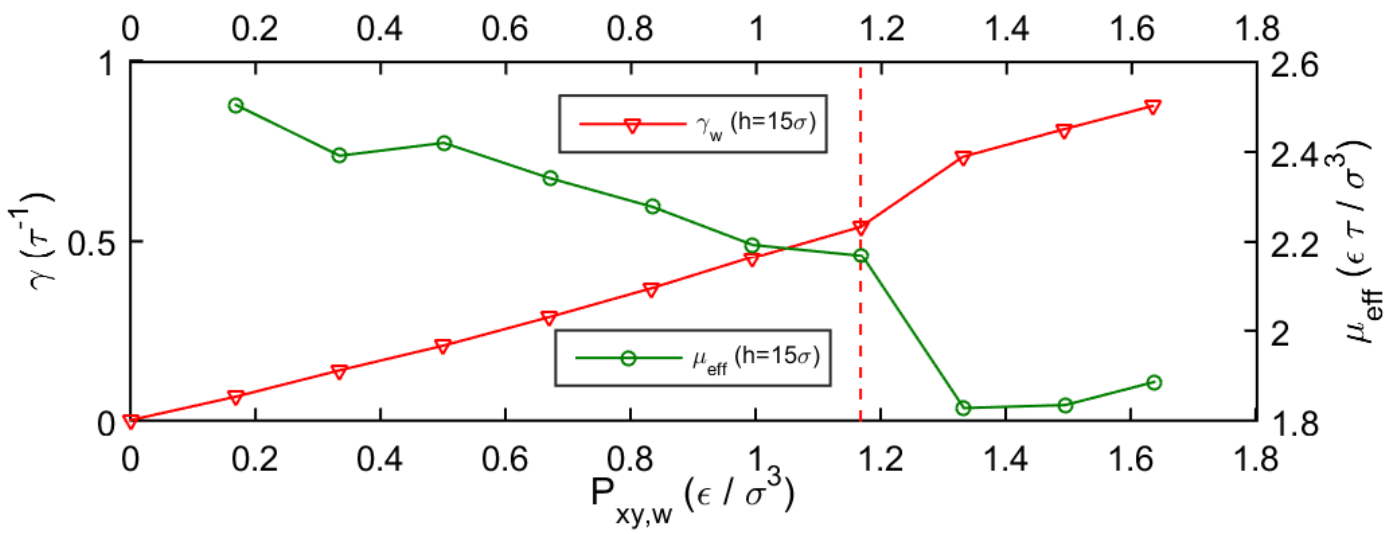

Fig. 13 Strain rate and effective apparent viscosity variation with wall shear stress 
apparent viscosity. In case of UTFM, $\gamma_{\mathrm{w}}$ continues again to linearly increase. In case of CTFM, $\mu_{\text {eff }}$ decreases gradually as $\mathrm{P}_{\mathrm{xy}, \mathrm{w}}$ increases due to slight increase in $\mathrm{T}_{\mathrm{fm}}$. At WSSL, it is clear that $\mu_{\text {eff }}$ decreases rapidly as a result of significant increase in $\mathrm{T}_{\mathrm{fm}}$. In UTFM, it can be seen that $\mu_{\text {eff }}$ seems to increase for increasing $\mathrm{P}_{\mathrm{xy}, \mathrm{w}}$. This increase in $\mu_{\text {eff }}$ is attributed to the effect of $\mathrm{T}_{\mathrm{fm}}$ which eventually leads to supercritical state (gas in behavior).

The relation between slip length $\mathrm{L}_{\mathrm{s}}$ and wall shear stress $\mathrm{P}_{\mathrm{xy}, \mathrm{w}}$ is presented in Fig. 14. With increasing wall shear stress up to $\sim 0.67 \epsilon / \sigma^{3}$ (for low wall shear stress values in CTFM), It can be seen that slip length changes slightly due to irrelevant change in the fluid inhomogeneity represented by contact density (see Fig. 8). The slip length then gradually decreases for further increase of wall shear stress up to $1.1681 \epsilon / \sigma^{3}$ (higher wall shear stress values in CTFM up to

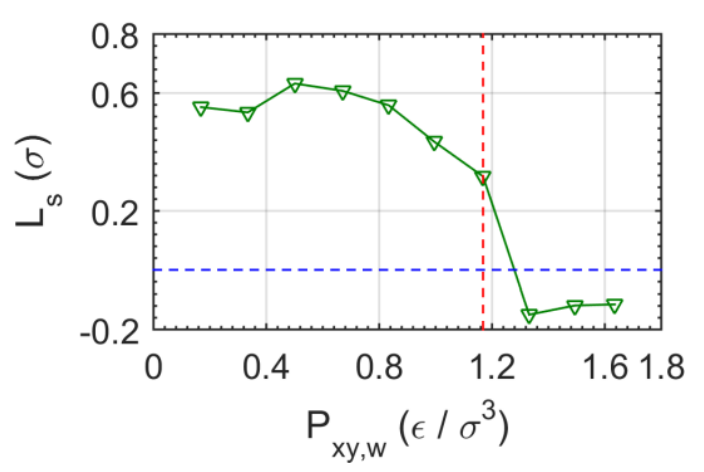

Fig. 14 Slip length variation with wall shear stress

WSSL). This is attributed to the gradual increase of the fluid inhomogeneity near wall clearly indicated in Fig. 8 which leads to higher resistance for fluid to slip. In case of UTFM $\left(\mathrm{P}_{\mathrm{xy}, \mathrm{w}}>1.1681 \epsilon / \sigma^{3}\right)$, the slip length suddenly decreases and then gradually approaches zero value (no slip BC) with increasing $\mathrm{P}_{\mathrm{xy}, \mathrm{w}}$ owing to the decrease of $\delta$ which leads to more friction between fluid and wall atoms at the interface. In spite of the decrease in the fluid inhomogeneity caused by significant increase of $\mathrm{T}_{\mathrm{fm}}$, the depletion layer thickness, however, seems to be the dominant factor influencing slip length in UTFM.

\section{Conclusions}

Molecular dynamics simulations of liquid argon confined between two parallel face centered cubic structured walls of nano channel are performed. The present research work focuses on the effect of wall shear stress on fluid properties and slip length. The mean fluid temperature is maintained nearly constant via adaptive thermal wall model. The effectiveness of the adaptive thermal wall is found to be limited by the wall shear stress limit (WSSL) after which neither the viscous heating nor the mean fluid temperature could be controlled.

The following conclusions can be drawn as follows:

1. The flow may be classified as controlled and uncontrolled temperature flow mode (CTFM and UTFM) related to the value of WSSL

2. In case of CTFM, in spite of maintaining the mean fluid temperature at almost constant level, the nonlinearity of temperature profile, which increases with increasing wall shear stress, causes the increase in fluid inhomogeneity near wall and consequently decrease of slip length.

3. In case of UTFM, both fluid temperature and pressure significantly increase. The depletion layer thickness, fluid inhomogeneity and viscosity decrease remarkably. The liquid argon unexpectedly turns into supercritical. The decrease of depletion layer thickness leads to more friction between fluid and wall atoms and therefore, the slip length also decreases remarkably.

\section{References}

[1] Allen, M.P. and D.J. Tildesley, Computer simulation of liquids. 2017: Oxford university press.

[2] Asproulis, N. and D. Drikakis, Boundary slip dependency on surface stiffness. Physical Review E, 2010. 81(6): p. 061503.

[3] Bao, L., N.V. Priezjev, H. Hu, and K. Luo, Effects of viscous heating and wall-fluid interaction energy on rate-dependent slip behavior of simple fluids. Physical Review E, 2017. 96(3): p. 033110.

[4] Barrat, J.-L., Influence of wetting properties on hydrodynamic boundary conditions at a fluid/solid interface. Faraday discussions, 1999. 112: p. 119-128.

[5] Barrat, J.-L. and L. Bocquet, Large slip effect at a nonwetting fluid-solid interface. Physical review letters, 1999. 82(23): p. 4671.

[6] Bernardi, S., B. Todd, and D.J. Searles, Thermostating highly confined fluids. The Journal of chemical physics, 2010. 132(24): p. 244706. 
[7] Bhadauria, R. and N. Aluru, A quasicontinuum hydrodynamic model for slit shaped nanochannel flow. The Journal of chemical physics, 2013. 139(7): p. 074109.

[8] Bocquet, L. and J.-L. Barrat, Hydrodynamic boundary conditions, correlation functions, and Kubo relations for confined fluids. Physical review E, 1994. 49(4): p. 3079.

[9] Bocquet, L. and J.-L. Barrat, Hydrodynamic properties of confined fluids. Journal of Physics: Condensed Matter, 1996. 8(47): p. 9297.

[10] Bocquet, L. and J.-L. Barrat, Flow boundary conditions from nano-to micro-scales. Soft matter, 2007. 3(6): p. 685-693.

[11] Chou, L.Y., K. Ming, and W.C. Chan, Strategies for the intracellular delivery of nanoparticles. Chemical Society Reviews, 2011. 40(1): p. 233-245.

[12] Cohen-Tanugi, D. and J.C. Grossman, Water desalination across nanoporous graphene. Nano letters, 2012. 12(7): p. 3602-3608.

[13] Edwards, B.J. and M. Dressler, A reversible problem in non-equilibrium thermodynamics: Hamiltonian evolution equations for non-equilibrium molecular dynamics simulations. Journal of nonnewtonian fluid mechanics, 2001. 96(1): p. 163-175.

[14] Evans, D.J., E. Cohen, and G.P. Morriss, Viscosity of a simple fluid from its maximal Lyapunov exponents. Physical Review A, 1990. 42(10): p. 5990.

[15] Ghorbanian, J. and A. Beskok, Scale effects in nano-channel liquid flows. Microfluidics and Nanofluidics, 2016. 20(8): p. 121.

[16] Ghorbanian, J., A.T. Celebi, and A. Beskok, A phenomenological continuum model for force-driven nano-channel liquid flows. The Journal of chemical physics, 2016. 145(18): p. 184109.

[17] Hansen, J. and I. McDonald, Theory of Simple Liquids (Academic, New York, 1986). 56 DA McQuarrie, Statistical Mechanics. 1976, Harper and Row, New York.

[18] Heister, E., E.W. Brunner, G.R. Dieckmann, I. Jurewicz, and A.B. Dalton, Are carbon nanotubes a natural solution? Applications in biology and medicine. ACS applied materials \& interfaces, 2013. 5(6): p. 18701891.

[19] Heyes, D.M., The liquid state: applications of molecular simulations. 1998: Wiley.
[20] Hinds, B.J., N. Chopra, T. Rantell, R. Andrews, V. Gavalas, and L.G. Bachas, Aligned multiwalled carbon nanotube membranes. Science, 2004. 303(5654): p. 62-65.

[21] Holland, D.M., D.A. Lockerby, M.K. Borg, W.D. Nicholls, and J.M. Reese, Molecular dynamics pre-simulations for nanoscale computational fluid dynamics. Microfluidics and Nanofluidics, 2015. 18(3): p. 461-474.

[22] Irving, J. and J.G. Kirkwood, The statistical mechanical theory of transport processes. $I V$. The equations of hydrodynamics. The Journal of chemical physics, 1950. 18(6): p. 817-829.

[23] Karniadakis, G., A. Beskok, and N. Aluru, Simple Fluids in Nanochannels. 2005: Springer.

[24] Khare, R., J. de Pablo, and A. Yethiraj, Molecular simulation and continuum mechanics study of simple fluids in nonisothermal planar couette flows. The Journal of chemical physics, 1997. 107(7): p. 25892596.

[25] Koplik, J., J.R. Banavar, and J.F. Willemsen, Molecular dynamics of fluid flow at solid surfaces. Physics of Fluids A: Fluid Dynamics, 1989. 1(5): p. 781-794.

[26] Lauga, E., M. Brenner, and H. Stone, Microfluidics: the no-slip boundary condition, in Springer handbook of experimental fluid mechanics. 2007, Springer. p. 1219-1240.

[27] Liang, Z. and P. Keblinski, Slip length crossover on a graphene surface. The Journal of chemical physics, 2015. 142(13): p. 134701.

[28] Liu, C. and Z. Li, Molecular dynamics simulation of composite nanochannels as nanopumps driven by symmetric temperature gradients. Physical review letters, 2010. 105(17): p. 174501.

[29] Liu, C. and Z. Li, On the validity of the Navier-Stokes equations for nanoscale liquid flows: The role of channel size. AIP advances, 2011. 1(3): p. 032108.

[30] Martini, A., H.-Y. Hsu, N.A. Patankar, and S. Lichter, Slip at high shear rates. Physical review letters, 2008. 100(20): p. 206001.

[31] Martini, A., A. Roxin, R. Snurr, Q. Wang, and S. Lichter, Molecular mechanisms of liquid slip. Journal of Fluid Mechanics, 2008. 600: p. 257-269. 
[32] Meier, K., A. Laesecke, and S. Kabelac, Transport coefficients of the Lennard-Jones model fluid. I. Viscosity. The Journal of chemical physics, 2004. 121(8): p. 36713687.

[33] Neto, C., D.R. Evans, E. Bonaccurso, H.-J. Butt, and V.S. Craig, Boundary slip in Newtonian liquids: a review of experimental studies. Reports on Progress in Physics, 2005. 68(12): p. 2859.

[34] Pahlavan, A.A. and J.B. Freund, Effect of solid properties on slip at a fluid-solid interface. Physical Review E, 2011. 83(2): p. 021602.

[35] Priezjev, N.V., Rate-dependent slip boundary conditions for simple fluids. Physical Review E, 2007. 75(5): p. 051605.

[36] Priezjev, N.V. and S.M. Troian, Molecular origin and dynamic behavior of slip in sheared polymer films. Physical review letters, 2004. 92(1): p. 018302.

[37] Raghunathan, A., J. Park, and N. Aluru, Interatomic potential-based semiclassical theory for Lennard-Jones fluids. The Journal of chemical physics, 2007. 127(17): p. 174701.

[38] Rapaport, D.C., R.L. Blumberg, S.R. McKay, and W. Christian, The art of molecular dynamics simulation. Computers in Physics, 1996. 10(5): p. 456-456.

[39] Semiromi, D.T. and A. Azimian, Nanoscale Poiseuille flow and effects of modified Lennard-Jones potential function. Heat and mass transfer, 2010. 46(7): p. 791-801.

[40] Shalek, A.K., J.T. Robinson, E.S. Karp, J.S. Lee, D.-R. Ahn, M.-H. Yoon, A. Sutton, M. Jorgolli, R.S. Gertner, and T.S. Gujral, Vertical silicon nanowires as a universal platform for delivering biomolecules into living cells. Proceedings of the National Academy of Sciences, 2010. 107(5): p. 1870-1875.

[41] Sokhan, V.P., D. Nicholson, and N. Quirke, Fluid flow in nanopores: Accurate boundary conditions for carbon nanotubes. The Journal of chemical physics, 2002. 117(18): p. 8531-8539.

[42] Squires, T.M. and S.R. Quake, Microfluidics: Fluid physics at the nanoliter scale. Reviews of modern physics, 2005. 77(3): p. 977.

[43] Suk, M. and N. Aluru, Molecular and continuum hydrodynamics in graphene nanopores. RSC Advances, 2013. 3(24): p. 9365-9372.

[44] Surwade, S.P., S.N. Smirnov, I.V. Vlassiouk, R.R. Unocic, G.M. Veith, S. Dai, and S.M. Mahurin, Water desalination using nanoporous single-layer graphene. Nature nanotechnology, 2015. 10(5): p. 459-464.

[45] Thomas, J.A. and A.J. McGaughey, Reassessing fast water transport through carbon nanotubes. Nano letters, 2008. 8(9): p. 2788-2793.

[46] Thomas, J.A., A.J. McGaughey, and O. Kuter-Arnebeck, Pressure-driven water flow through carbon nanotubes: Insights from molecular dynamics simulation. International journal of thermal sciences, 2010. 49(2): p. 281-289.

[47] Thompson, P.A. and M.O. Robbins, Shear flow near solids: Epitaxial order and flow boundary conditions. Physical Review A, 1990. 41(12): p. 6830.

[48] Thompson, P.A. and S.M. Troian, A general boundary condition for liquid flow at solid surfaces. Nature, 1997. 389(6649): p. 360.

[49] Travis, K.P. and K.E. Gubbins, Poiseuille flow of Lennard-Jones fluids in narrow slit pores. The Journal of Chemical Physics, 2000. 112(4): p. 1984-1994.

[50] Travis, K.P., B. Todd, and D.J. Evans, Departure from Navier-Stokes hydrodynamics in confined liquids. Physical Review E, 1997. 55(4): p. 4288.

[51] Wang, G.J. and N.G. Hadjiconstantinou, Why are fluid densities so low in carbon nanotubes? Physics of Fluids, 2015. 27(5): p. 052006.

[52] Wang, L., M.S. Boutilier, P.R. Kidambi, D. Jang, N.G. Hadjiconstantinou, and R. Karnik, Fundamental transport mechanisms, fabrication and potential applications of nanoporous atomically thin membranes. Nature Nanotechnology, 2017. 12(6): p. 509-522.

[53] Wu, W., H. Chen, and D. Sun, The morphologies of Lennard-Jones liquid encapsulated by carbon nanotubes. Physics Letters A, 2013. 377(3): p. 334-337.

[54] Xie, X., A.M. Xu, S. Leal-Ortiz, Y. Cao, C.C. Garner, and N.A. Melosh, Nanostrawelectroporation system for highly efficient intracellular delivery and transfection. ACS nano, 2013. 7(5): p. 4351-4358.

[55] Yong, X. and L.T. Zhang, Thermostats and thermostat strategies for molecular 
dynamics simulations of nanofluidics. The Journal of chemical physics, 2013. 138(8): p. 084503.

تحقيق في إنهيار معادلات نافير- ستوكس في السريان النانوي

\section{ملخص الرسالة}

تقدم الدراسة تحقيقا في إنهيار معادلات نافير - ستوكس

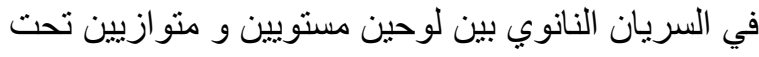

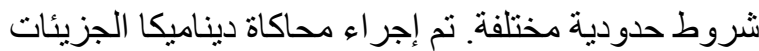

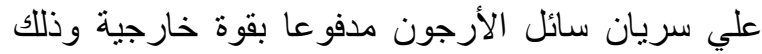

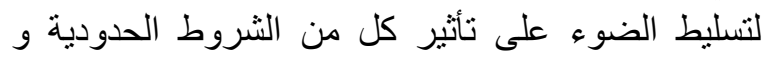

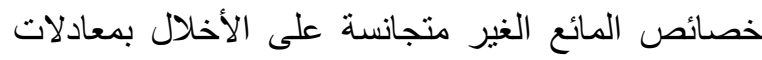

$$
\text { نافير ستوكس. }
$$

الدراسة الحالية أخذت في الأعنبار تأثثر إتساع

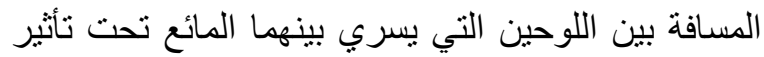
قيم مختلفة من إجهاد القص عند الجدران وذللك لنفس البنية

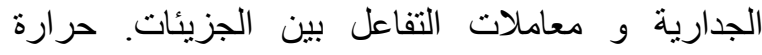

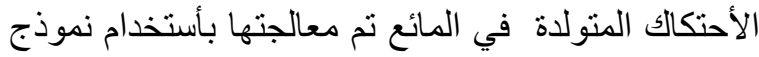

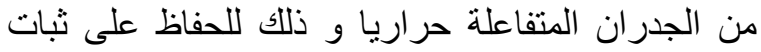

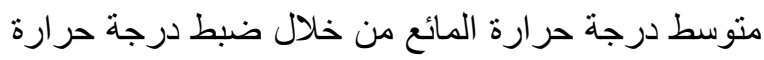

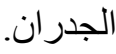

نتائج محاكاة ديناميكا الجزيئات أظهرت تصنيف

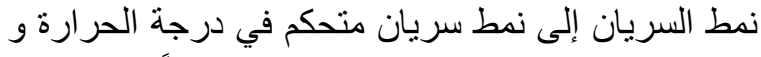
آخر غير متحكم في درجة حرارة مرتبط الجياً بحد إجهاد

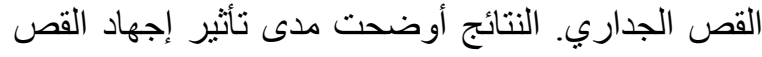

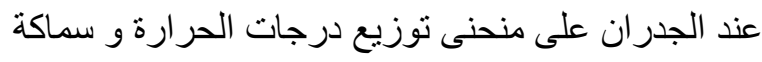

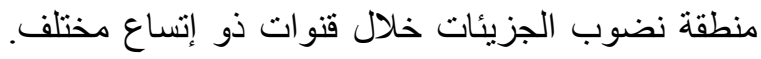

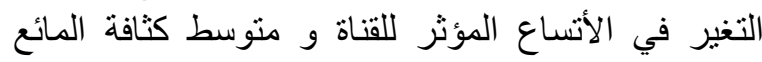

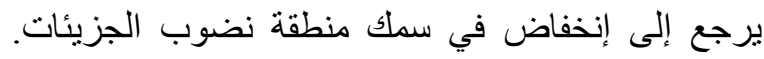

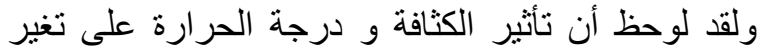

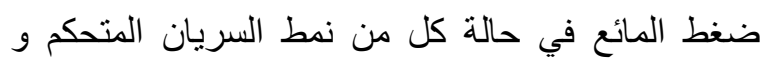
الغير متحكم في درجة حرارة في حين أن تحول المائع
إلى الحالة الفوق حرجة بعد حد إجهاد القص الجداري يرجع إلى التغير الملموس في درجة الحرارة و الضغطة.

النتائج أظهرت تغير واضح في عدم تجانس

المائع بالقرب من الجدران و كذلك طول الأنزلاق مرتبطاً

بإجهاد القص عند الجدران و إتساع القناة. لقد وجد أن إنهيار معادلات نافير ستوكس يمكن إبرازها من خلال النسبة المئوية في الخطأ الخاص بحساب ندفق السريان الكتلي. و لقد لوحظ إختلاف قيم في النتائج الخاصة بمعادلات نافير ستوكس مقارنة بنتائج محاكاة ديناميكا الجزيئات إلا أنه يمكن إهمال هذا الأختلاف عندما يكون عدم تجانس المائع أقل تأثنير ا أو عندما يكون طول الأنزلاق قريب من الصفر. 